\title{
Mapeamento de pesquisas sobre aprendizagem docente em Comunidades de Prática constituídas no OBEDUC
}

\author{
A teacher learning mapping study in Communities of Practice constituted in OBEDUC
}

\author{
Douglas da Silva Tinti ${ }^{1}$
}

Ana Lúcia Manrique ${ }^{2}$

\begin{abstract}
Resumo
O presente mapeamento foi realizado a partir de pesquisas desenvolvidas no âmbito do Programa Observatório da Educação (OBEDUC), as quais utilizaram a Teoria Social da Aprendizagem para compreender aprendizagens docentes em contextos formativos com professores que ensinam matemática. Foram mapeados seis estudos vinculados a dois grupos de pesquisa distintos. Três deles analisaram uma Comunidade de Prática (CoP), constituída na cidade de Paranavaí/PR, e os outros três, uma CoP na cidade de São Paulo/SP. Embora as pesquisas analisadas indiquem que o movimento de constituição das CoP se deu de maneira diversificada, é importante destacar que os empreendimentos em que se engajaram foram negociados em função das demandas formativas de seus membros. Nesse contexto, fica evidente um movimento de compromisso mútuo entre os membros da $\mathrm{CoP}$ em relação aos empreendimentos e à manutenção da comunidade.
\end{abstract}

Palavras-chave: OBEDUC; Comunidades de Prática; Formação de Professores; Aprendizagem Docente

\begin{abstract}
This mapping study was based on research developed in the Observatory of Education Program (OBEDUC) that used the Social Theory of Learning to seek to understand teacher learning in formative contexts with teachers who teach mathematics. Six studies were selected from two different research groups. Three of these studies analyzed a Communities of Practice (CoP) constituted in the city of Paranavaí/PR and the other three studies investigated a $\mathrm{CoP}$ in the city of São Paulo/SP. The analyzed studies indicate that the formation of CoP movement has diversified way. Nevertheless, it is important to emphasize that the enterprises in which they were engaged were negotiated according to the formative demands of their members. In this context, a movement of mutual commitment between CoP members regarding entrepreneurship and community.
\end{abstract}

Keywords: OBEDUC; Communities of Practice; Teacher Education; Teacher Learning

\section{Introdução}

No cenário nacional, temos percebido, nos últimos anos, a ampliação de programas e políticas públicas voltadas à pesquisa e à formação de professores. Dentre esses programas,

1 Doutor em Educação Matemática pela Pontifícia Universidade Católica de São Paulo. Professor da Universidade Cidade de São Paulo, Brasil. Email: douglastinti@uol.com.br

2 Doutora em Educação pela Pontifícia Universidade Católica de São Paulo. Professora da Pontifícia Universidade Católica de São Paulo, Brasil. Email: analuciamanrique @gmail.com

Zetetiké, Campinas, SP, v.25, n1, jan./abr.2017, p.186-203

ISSN 2176-1744 
destaca-se o Programa Observatório da Educação (OBEDUC), cujo objetivo é fortalecer o diálogo entre a comunidade acadêmica, os gestores das políticas nacionais de Educação e os diversos atores envolvidos no processo educacional.

Nesse direcionamento, o estudo realizado por Oliveira (2015) aponta que

os projetos submetidos ao OBEDUC têm oportunizado a integração entre pós-graduação, cursos de formação de professores e escolas de educação básica, possibilitando o desenvolvimento profissional a futuros professores e professores em exercício na escola básica. Com isso o OBEDUC tem se configurado como um programa que fomenta estudos sobre a formação de professores que ensinam Matemática, já que muitos dos projetos são da área de Educação Matemática, sendo, portanto, um lócus de diferentes experiências de pesquisas e de formação de professores. (p. 2-3)

Esse estudo indica, ainda, que a produção de conhecimento científico gerada pelas pesquisas desenvolvidas no âmbito do OBEDUC e os processos formativos, empreendidos pelos envolvidos nos projetos, têm sinalizado indícios de impacto desse tipo de programa na educação brasileira. Esse fato nos motivou a olhar para a produção (dissertações e teses) vinculada a tais projetos.

Com base nesse apontamento, optamos por realizar um levantamento no site da CAPES $^{3}$, no sentido de quantificar e identificar os projetos atrelados à área de Educação Matemática. Desse levantamento, constatamos que 16,46\% dos projetos aprovados, no período de 2006 a 2012, eram relacionados à área de Ensino de Matemática, como evidenciado na Tabela 1.

Tabela 1 - Número de projetos aprovados no âmbito do OBEDUC.

\begin{tabular}{|c|c|c|} 
Edital & $\begin{array}{c}\mathbf{N}^{\mathbf{o}} \text { de Projetos } \\
\text { Aprovados }\end{array}$ & $\begin{array}{c}\mathbf{N}^{\mathbf{0}} \text { de projetos envolvendo o "Ensino de } \\
\text { Matemática" }\end{array}$ \\
\hline $\mathrm{N}^{\mathbf{o}} 01 / 2006$ & 28 & 1 \\
\hline $\mathrm{N}^{\circ} 01 / 2008$ & 28 & 4 \\
\hline $\mathrm{N}^{\mathbf{o} 38 / 2010}$ & 80 & 18 \\
\hline $\mathrm{N}^{\mathbf{o}} 49 / 2012$ & 90 & 17 \\
\hline Total & $\mathbf{2 4 3}$ & $\mathbf{4 0}$ \\
\hline
\end{tabular}

Fonte: elaboração dos autores a partir dos dados disponibilizados no site da Capes.

De posse de informações dos projetos aprovados, que envolviam estudos sobre o ensino de matemática, procuramos identificar quais deles utilizavam a Teoria Social da Aprendizagem (Wenger, 1998) em suas referências. Encontramos dois projetos que se enquadravam nos parâmetros por nós delimitados (Quadro 1).

Quadro 1 - Relação de projetos aprovados no OBEDUC que discutem aprendizagens docentes situadas em CoP.

\begin{tabular}{|c|l|c|c|}
\hline Edital & \multicolumn{1}{|c|}{ Título do Projeto } & Instituição \\
\hline$N^{\circ} 38 / 2010$ & $\begin{array}{l}\text { Educação Matemática de professores que ensinam } \\
\text { Matemática }\end{array}$ & UEL \\
\hline
\end{tabular}

\footnotetext{
${ }^{3}$ Retirado em 15 de abril de 2016, de http://www.capes.gov.br/
} 


\begin{tabular}{|l|l|c|}
\hline No 49/2012 & $\begin{array}{l}\text { Rede Colaborativa de práticas na formação de professores } \\
\text { que ensinam Matemática: múltiplos olhares diálogos e } \\
\text { contextos }\end{array}$ & $\begin{array}{c}\text { UFSCAR / PUC- } \\
\text { SP / UFABC }\end{array}$ \\
\hline
\end{tabular}

Fonte: elaboração dos autores a partir dos dados disponibilizados no site da Capes.

Notamos que os referidos projetos estão atrelados a grupos de pesquisa que desenvolvem pesquisas na área de Educação Matemática e apresentam resultados correlatos e significativos no que tange à discussão sobre aprendizagens docentes em Comunidades de Prática (CoP). Os grupos são:

a) Grupo de Estudos e Pesquisa sobre a Formação de Professores que Ensinam Matemática (GEPEFOPEM) da UEL.

b) Grupo de Pesquisa Professor de Matemática: formação, profissão, saberes e trabalho docente da PUC-SP.

A partir desse levantamento, relacionamos a produção desses grupos e elegemos aquelas pesquisas que investigaram aprendizagens docentes evidenciadas em CoP, constituídas para o projeto aprovado no OBEDUC, com o objetivo de apresentar uma síntese.

De posse das pesquisas, procedemos uma leitura, na íntegra, dos documentos e elaboramos uma síntese de cada uma delas, considerando: a) o objetivo do trabalho; b) o contexto da pesquisa e da coleta de dados; c) a metodologia utilizada; e d) os principais resultados apontados.

A seguir, faremos a apresentação das pesquisas, segmentando-as pelos Grupos de Pesquisas em que estão vinculadas para, posteriormente, tecer algumas análises sobre a produção mapeada.

\section{Pesquisas desenvolvidas pelo GEPEFOPEM}

O GEPEFOPEM é um grupo de pesquisas, vinculado ao Programa de Pós-Graduação em Ensino de Ciências e Educação Matemática do Centro de Ciências Exatas da UEL e é coordenado pela professora Dra. Márcia Cristina de Costa Trindade Cyrino. Esse grupo tem como proposta: estudar e investigar os fundamentos e os processos de constituição dos conhecimentos/saberes docentes na formação inicial (curso de licenciatura em Matemática e Pedagogia), bem como a formação em serviço de professores em matemática.

Como mencionado anteriormente, no Edital No 38/2010, a UEL teve aprovação do projeto intitulado: "Educação Matemática de professores que ensinam Matemática". Tal projeto foi desenvolvido no período de 2010 a 2015, e teve como objetivo geral fomentar a produção acadêmica relativa à formação de professores que ensinam matemática e à formação de recursos humanos em Educação Matemática na Educação Básica. De acordo com o referido projeto, a estratégia adotada pelo GEPEFOPEM para a condução das pesquisas relacionada engloba a adoção de uma agenda de trabalho colaborativo e a constituição de uma CoP de professores que ensinam matemática. A CoP constituída foi formada por pesquisadores, futuros professores de matemática e professores de matemática que atuam na Educação Básica. 
Dentre as produções desse grupo de pesquisa, considerando os parâmetros delimitados anteriormente, elegemos as dissertações de Rocha (2013) e de Oliveira (2014) e a tese de Garcia (2014) para compor nosso mapeamento.

Antes de seguirmos, é importante destacar que as três pesquisas analisadas investigaram a Comunidade de Prática de Professores que Aprendem e Ensinam Matemática (CoP-PAEM), organizada no ano de 2011, na cidade de Paranavaí/PR, de forma a propiciar um contexto para as pesquisas e para o desenvolvimento profissional de professores em serviço, no qual fosse possível conhecer que elementos da prática oportunizaram aprendizagens de professores de matemática.

A pesquisa realizada por Rocha (2013) investigou um contexto de formação, organizado em reuniões semanais em um colégio estadual de Paranavaí. Participaram dessa formação seis professoras dos anos finais de Ensino Fundamental, uma professora recémformada, uma professora formadora e o investigador. Rocha (2013) aponta que, ao longo do período da pesquisa, foram constatados elementos que evidenciaram como o grupo investigado foi se constituindo em uma CoP.

O autor procurou compreender como esse contexto formativo colabora para aprendizagens de professores que ensinam matemática. Para tanto, elegeu a seguinte questão para direcionar sua pesquisa: "Que elementos do contexto de uma Comunidade de Prática de professores de matemática permitem aprendizagens de seus membros, ao lidarem com empreendimentos na busca de aprender e ensinar frações?"

No período de março de 2011 a junho de 2012, Rocha (2013) participou de 40 encontros da CoP-PAEM e considerou, como instrumento de coleta de dados, o diário de campo do investigador, as gravações em áudio dos encontros e os registros escritos, produzidos pelos membros da CoP.

Dentre os empreendimentos que a CoP-PAEM se engajou no período analisado, Rocha (2013) tentou identificar episódios em que fosse possível evidenciar processos de negociação de significados, ocorridos na articulação e no desenvolvimento do empreendimento denominado "Estudo a respeito do conceito de fração".

Em síntese, Rocha (2013) aponta que a análise realizada permitiu identificar elementos da prática da comunidade investigada que possibilitaram aprendizagens a seus membros. Tais elementos da prática são nomeados pelo autor de oportunidades. Sendo assim, foram identificadas as oportunidades de: refletir/discutir a respeito da prática pedagógica; compartilhar experiências; elaborar material manipulativo, explorando suas potencialidades; elaborar e resolver tarefas associadas ao material manipulativo construído; refletir sobre aplicação dessas tarefas em sala de aula; enfrentar desafios, como por exemplo, ter suas aulas audiogravadas ou videogravadas; questionar e ser questionado (compromisso com a justificação); e refletir a respeito do processo de formação continuada.

A pesquisa realizada por Oliveira (2014) assume a perspectiva qualitativa, do tipo pesquisa intervenção, e objetivou identificar e analisar que empreendimentos articulados e Zetetiké, Campinas, SP, v.25, n1, jan./abr.2017, p.186-203 
desenvolvidos na/pela CoP-PAEM resultaram em aprendizagens de seus participantes, no que concerne a seu conhecimento profissional, especificamente aspectos do Raciocínio Proporcional, parte do conhecimento matemático constituído por esses professores; e analisar que conhecimentos da matemática os participantes dessa comunidade de prática mobilizavam nas ações de resolver, discutir e refletir a respeito de problemas envolvendo proporção/proporcionalidade. Para tanto, elegeu a Teoria Social da Aprendizagem (Wenger, 1998) como referencial teórico, e o seguinte questionamento como direcionador de sua pesquisa: "Que elementos da prática de uma CoP oportunizam aprendizagens relacionadas ao conhecimento matemático de professores de matemática em ações de resolver, discutir e analisar problemas envolvendo proporção/proporcionalidade?"

Vale salientar que houve alteração na quantidade de membros dado a inclusão e a saída de alguns deles. No momento em que Oliveira (2014) concluiu a pesquisa, a CoPPAEM era composta por sete professores de matemática, de diferentes escolas de Paranavaí, e por duas formadoras-pesquisadoras.

Como instrumentos de coleta de dados foram considerados: diários de campo, gravações em áudio e suas respectivas transcrições, além de registros escritos dos participantes em folhas de tarefas.

Para atingir o objetivo proposto, Oliveira (2014) destaca que foram selecionadas duas das ações desencadeadas pela CoP-PAEM: resolução e discussão de estratégias de resolução de problemas que envolvem proporção/proporcionalidade; e reflexão a respeito de estratégias e justificações, apresentadas na ação anterior, com o apoio da literatura sobre o tema desenvolvidas na/pela CoP-PAEM.

Ao analisar as ações desencadeadas, Oliveira (2014) aponta que foi possível perceber que a CoP-PAEM se engajou em diferentes empreendimentos, tais como: apresentar resoluções, justificando o raciocínio para os demais colegas; elaborar estratégias para a resolução dos problemas; resolver problemas, envolvendo proporção/proporcionalidade sem o uso de recursos algébricos; e desenvolver estudo teórico de alguns conceitos, ideias e formas de pensar subjacentes ao Raciocínio Proporcional.

Dentre outras coisas, Oliveira (2014) salienta que, nos processos de negociação de significados, desencadeados pela resolução, discussão e reflexão a respeito de problemas e de algumas resoluções apresentadas, foi possível identificar aprendizagens dos participantes da CoP-PAEM relativas a aspectos de seu conhecimento matemático, como por exemplo, a mobilização de algumas estruturas do Raciocínio Proporcional. Ao descrever a análise dos dados, a autora ilustra os episódios, em que se é possível evidenciar a negociação de significados, e apresenta um aprofundamento, utilizando-se das discussões teóricas sobre o Raciocínio Proporcional.

Os dados apontam que a CoP-PAEM se constituiu num espaço comunicativo, em que seus pares puderam compartilhar seus repertórios e, nesse contexto, foi possível evidenciar aprendizagens, como por exemplo, o de perceber que a forma como eram abordados 
frequentemente os conteúdos matemáticos em sala de aula não propiciava o desenvolvimento de raciocínios matemáticos mais livres.

Oliveira (2014) destaca que, a partir das análises, foram identificados elementos da prática da CoP-PAEM que oportunizaram aprendizagens dos professores participantes dessa CoP, são eles: a resolução de problemas; o compartilhamento e a justificação de suas produções; o estudo de textos teóricos a respeito do Raciocínio Proporcional; e a oportunidade de ser questionado e a reflexão a respeito da produção escrita/oral desencadeada a partir de alguns problemas resolvidos. Por fim, a autora ressalta que tudo isso foi possível em função do compromisso de cada participante, firmado com a CoP-PAEMe com cada um de seus participantes, e da responsabilidade assumida, com relação às suas aprendizagens e à de seus colegas professores de matemática.

A pesquisa realizada por Garcia (2014) também analisou a CoP-PAEM investigada por Oliveira (2014). Teve por objetivo identificar e analisar empreendimentos e ações negociadas na CoP-PAEM que evidenciaram trajetórias de aprendizagem de seus participantes, relacionadas a aspectos envolvidos na constituição da identidade profissional de professores que ensinam matemática.

Para tanto, a autora elegeu a seguinte questão para nortear sua pesquisa: "Que elementos da prática de uma Comunidade de Prática de professores que ensinam matemática promovem o desenvolvimento da identidade profissional de professor?"

É importante destacar que Garcia (2014) compreende o desenvolvimento da identidade profissional dos professores à luz da Teoria Social da Aprendizagem (Wenger, 1998), a qual considera a identidade profissional como um fenômeno de transformação pessoal e contínua, em estreita relação com o processo de aprendizagem e, portanto, inerente à participação ou à pertença nas Comunidades de Prática.

Para responder a esse questionamento, a autora centrou atenção nas ações negociadas e desenvolvidas pelos membros da CoP-PAEM no empreendimento denominado "Estudo do Raciocínio Proporcional", desenvolvido no período de julho de 2012 a junho de 2013.

Garcia (2014) relata que, nesse período, os membros da CoP-PAEM negociaram e se engajaram no desenvolvimento de cinco ações, a saber: 1) resolução e discussão de problemas que envolvem proporção/proporcionalidade; 2) estudo de textos a respeito do raciocínio proporcional, 3) proposição de problemas envolvendo proporção/ proporcionalidade; 4) análise de estratégias e justificações apresentadas na ação (1) com apoio na literatura; e 5) proposição e análise de problemas com potencial para mobilizar o Raciocínio Proporcional.

Diante desse cenário, para atingir o objetivo proposto, Garcia (2014) aponta que selecionou episódios em que os membros da CoP tiveram a oportunidade de negociar diversos significados e construir trajetórias de aprendizagem a respeito de conhecimentos profissionais. A partir desses episódios, a autora procura evidenciar elementos que, segundo sua interpretação, foram relevantes para a construção dessa trajetória de aprendizagem. 
Contudo, Garcia (2014) pontua que tais resultados sugerem que um processo de formação continuada, estruturado a partir da articulação desses elementos numa perspectiva de desenvolvimento profissional de professores que ensinam matemática, com uma dinâmica que permita diferentes modos de participação e favoreça a interação, a reflexão e a construção de relações de respeito e confiança, é uma alternativa às propostas de formação de professores, que privilegiam cursos ou treinamentos.

Atentando a essa produção do GEPEFOPEM, é importante destacar a coerência das pesquisas com o referencial teórico adotado (Wenger, 1998). Todas elas fazem menção aos elementos que ajudam a definir um grupo como uma CoP (Comunidade, Domínio e Prática), bem como àqueles que compõem as dimensões da prática da $\mathrm{CoP}$ (engajamento/compromisso mútuo, empreendimento conjunto/articulado e repertório compartilhado).

Considerando os referidos componentes, optamos por sintetizá-los em quadros. O Quadro 2 apresenta, para cada uma das pesquisas, a indicação dos elementos que possibilitaram aos autores caracterizar o grupo como uma $\mathrm{CoP}$.

Quadro 2 - Análise de pesquisas desenvolvidas pelo GEPEFOPEM por meio da organização da CoP.

\begin{tabular}{|c|c|c|c|}
\hline Pesquisa & Membros da CoP & Domínio & Prática \\
\hline $\begin{array}{l}\text { Rocha } \\
\text { (2013) }\end{array}$ & $\begin{array}{l}\text { Seis professoras dos } \\
\text { anos finais de Ensino } \\
\text { Fundamental, uma } \\
\text { professora recém- } \\
\text { formada, uma } \\
\text { professora formadora e } \\
\text { a pesquisadora }\end{array}$ & $\begin{array}{l}\text { A formação continuada de } \\
\text { professores que ensinam } \\
\text { matemática }\end{array}$ & $\begin{array}{c}\text { Reflexão a respeito da prática } \\
\text { pedagógica; produção de material } \\
\text { manipulativo; elaboração de tarefas } \\
\text { associadas ao material manipulativo } \\
\text { produzido; aplicação das tarefas em sala } \\
\text { de aula; relato da aplicação das tarefas } \\
\text { em sala de aula e reflexão a respeito da } \\
\text { aplicação; estudo de artigos; registros } \\
\text { feitos pelos membros do grupo a } \\
\text { respeito das impressões deles sobre a } \\
\text { participação nos encontros }\end{array}$ \\
\hline $\begin{array}{c}\text { Oliveira } \\
(2014)\end{array}$ & $\begin{array}{c}\text { Pesquisadores e } \\
\text { professores da Educação } \\
\text { Básica que ensinam } \\
\text { matemática }\end{array}$ & A formação de professores & $\begin{array}{l}\text { Desenvolvimento de diferentes } \\
\text { empreendimentos negociados e } \\
\text { articulados de forma a atender aos } \\
\text { interesses dos membros da CoP }\end{array}$ \\
\hline $\begin{array}{l}\text { Garcia } \\
(2014)\end{array}$ & $\begin{array}{c}\text { Pesquisadores e } \\
\text { professores da Educação } \\
\text { Básica que ensinam } \\
\text { matemática }\end{array}$ & $\begin{array}{l}\text { Desenvolvimento } \\
\text { profissional do professor } \\
\text { de matemática e } \\
\text { constituição de sua } \\
\text { identidade profissional }\end{array}$ & $\begin{array}{c}\text { Negociação constante de } \\
\text { empreendimentos e, também, ingresso } \\
\text { de novos membros e os interesses } \\
\text { trazidos por eles }\end{array}$ \\
\hline
\end{tabular}

Fonte: elaborado a partir da análise das respectivas pesquisas.

No Quadro 3, expomos, para cada uma das pesquisas, a prática da $\mathrm{CoP}$, considerando os elementos indicados por Wenger (1998).

Quadro 3 - Análise de pesquisas desenvolvidas pelo GEPEFOPEM por meio das dimensões da prática da CoP 
DOI: http://dx.doi.org/10.20396/zet.v25i1.8647770

\begin{tabular}{|c|c|c|c|}
\hline $\begin{array}{l}\text { Rocha } \\
(2013)\end{array}$ & Aprender e ensinar frações & $\begin{array}{c}\text { Estudos dos temas SAEB e } \\
\text { Prova Brasil; estudo a } \\
\text { respeito do conceito de } \\
\text { fração }\end{array}$ & $\begin{array}{l}\text { Impressões sobre processos } \\
\text { de ensino e relatos, conceitos } \\
\text { matemáticos e pedagógicos, } \\
\text { histórias experienciadas na } \\
\text { aplicação de tarefas em sala } \\
\text { de aula }\end{array}$ \\
\hline $\begin{array}{l}\text { Oliveira } \\
(2014)\end{array}$ & $\begin{array}{c}\text { Compartilhar informações, } \\
\text { materiais didáticos, ajudar } \\
\text { uns aos outros na } \\
\text { elaboração de estratégias } \\
\text { para a resolução de } \\
\text { problemas ou na } \\
\text { organização de dinâmicas } \\
\text { de aulas }\end{array}$ & $\begin{array}{l}\text { Estudo dos temas SAEB, } \\
\text { Prova Brasil e IDEB; } \\
\text { estudo dos Números } \\
\text { Racionais e estudo do } \\
\text { Raciocínio Proporcional }\end{array}$ & $\begin{array}{l}\text { Impressões dos processos de } \\
\text { ensino e de aprendizagem, } \\
\text { relatos de práticas } \\
\text { pedagógicas, rotinas }\end{array}$ \\
\hline $\begin{array}{l}\text { Garcia } \\
(2014)\end{array}$ & $\begin{array}{l}\text { Negociação de } \\
\text { empreendimentos }\end{array}$ & $\begin{array}{l}\text { Estudo dos temas SAEB, } \\
\text { Prova Brasil e IDEB; } \\
\text { estudo dos Números } \\
\text { Racionais e estudo do } \\
\text { Raciocínio Proporcional }\end{array}$ & $\begin{array}{l}\text { Caderno de anotações dos } \\
\text { membros da CoP, impressões } \\
\text { dos processos de ensino e de } \\
\text { aprendizagem, relatos de } \\
\text { práticas pedagógicas, rotinas, } \\
\text { resoluções de exercícios. }\end{array}$ \\
\hline
\end{tabular}

Fonte: elaborado a partir da análise das respectivas pesquisas.

Vale destacar que é perceptível o engajamento do GEPEFOPEM no que tange à cultivação de CoP na cidade do estado do Paraná, o que tem contribuído para a formação de muitos professores, pesquisadores e futuros professores de matemática.

\section{Pesquisas desenvolvidas pelo Grupo de Pesquisa "Professor de Matemática: formação, profissão, saberes e trabalho docente" da PUC-SP}

Desde o início de suas atividades, no ano de 2005, o Grupo de Pesquisa "Professor de Matemática: formação, profissão, saberes e trabalho docente" tem concentrado seus estudos e pesquisas nos processos de formação inicial e continuada de professores que ensinam matemática. Atualmente, o grupo é coordenado pelas professoras Ana Lúcia Manrique e Maria Cristina Souza de Albuquerque Maranhão.

Em relação à experiência desse grupo com o OBEDUC, é importante destacar que, desde a implementação do OBEDUC, esse mesmo grupo de pesquisa da PUC-SP teve três projetos aprovados. Dois foram propostos individualmente, um no edital de 2008 (coordenado pela Profa. Dra. Laurizete Ferragut Passos) e outro em 2010 (coordenado pela Profa. Dra. Ana Lúcia Manrique), ambos já finalizados. O terceiro projeto vinculado ao OBEDUC, proposto pela Dra. Renata Prenstteter Gama, da Universidade Federal de São Carlos (UFSCar), em parceria com a PUC-SP e a Universidade Federal do ABC (UFABC), foi aprovado no edital de 2012. Esse projeto está em andamento e é intitulado "Rede Colaborativa de práticas na formação de professores que ensinam Matemática: múltiplos olhares, diálogos e contextos". O projeto é coordenado, na PUC-SP, pela Profa. Dra. Laurizete Ferragut Passos, e tem a Profa. Dra. Ana Lúcia Manrique como pesquisadora participante. Esse projeto se vincula a outros dois Programas de Pós-Graduação da PUC-SP, nos quais a coordenadora do projeto atua como docente. São eles: o Programa de Pósgraduação em Psicologia da Educação e o Programa de Pós-graduação em Educação: 
Formação de Formadores.

Sendo esse projeto vinculado ao OBEDUC constituído em rede, a PUC-SP é um núcleo. Em função das bolsas ${ }^{4}$ concedidas no edital de 2012, o núcleo PUC-SP foi composto por um docente coordenador, estudantes de Pós-graduação (mestrado e doutorado), licenciandos em Pedagogia, licenciandos em Matemática e professores que ensinam matemática nos anos iniciais e finais do Ensino Fundamental na rede pública da cidade de São Paulo.

Ao iniciar o trabalho com o núcleo e com o desenvolvimento da pesquisa de Silva (2015), o Grupo de Pesquisa foi percebendo que o núcleo estava se constituindo em uma CoP (Wenger, 1998), fato que demandou novos estudos ao grupo e mobilizou a constituição de um subgrupo ${ }^{5}$ de estudos, a fim de estudar os referenciais teóricos que subsidiassem os trabalhos na CoP. Nesse sentido, o projeto OBEDUC, desenvolvido pelo núcleo PUC-SP, não foi concebido a partir de tal referencial teórico, mas ele tem sido utilizado pelos pesquisadores como uma lente teórica (Lerman, 2010) para a análise da prática desse núcleo.

Para compor nosso mapeamento, selecionamos a dissertação de Silva (2015) e a de Barros (2016) e a tese de Tinti (2016). Todas investigaram a mesma CoP, denominada CoP PUC-SP. Essa CoP é composta por licenciandos em Matemática e em Pedagogia, professores que ensinam matemática nos anos iniciais e finais do Ensino Fundamental da Educação Básica e pesquisadores em Educação e Educação Matemática.

A pesquisa desenvolvida por Silva (2015) foi a primeira concluída no projeto vinculado ao OBEDUC, do edital de 2012. A pesquisa também assume a Teoria Social da Aprendizagem, de Wenger (1998), como embasamento teórico e teve por objetivo identificar quais negociações de significado, envolvendo a Resolução de Problemas, ocorreram no núcleo da PUC-SP. Para tanto, a autora elegeu a seguinte questão de pesquisa: "Quais negociações de significado envolvendo a Resolução de Problemas ocorreram na Comunidade de Prática (CoP) do projeto vinculado ao OBEDUC (núcleo da PUC-SP)?”

No momento da realização da pesquisa, o núcleo da PUC-SP era constituído por: seis professores que ensinam matemática na Educação Básica, sendo três dos anos iniciais e três dos anos finais, três licenciandos em Pedagogia, três licenciandos em Matemática, dois mestrandos, dois doutorandos e duas doutoras. O núcleo iniciou suas atividades no mês de junho de 2013, e Silva (2015) indica que, ao longo do tempo, ele foi se constituindo em uma CoP. Os encontros da CoP foram realizados, quinzenalmente, aos sábados, nas dependências do câmpus Marquês de Paranaguá da PUC-SP.

Para atingir o objetivo proposto, Silva (2015) elegeu a perspectiva da pesquisa qualitativa e utilizou os seguintes instrumentos para a coleta de dados: as transcrições das

\footnotetext{
${ }^{4}$ Neste edital, estavam previstas: uma bolsa para o coordenador, uma bolsa para doutorado, três bolsas para mestrado, seis bolsas para licenciandos e seis bolsas para professores da Educação Básica.

${ }^{5}$ Os membros do Grupo de Pesquisa, envolvidos com o projeto aprovado no OBEDUC, se reuniam uma vez por mês para estudar o referencial teórico. Os demais membros do Grupo de Pesquisa foram convidados a participar destas reuniões "extras".
}

Zetetiké, Campinas, SP, v.25, n1, jan./abr.2017, p.186-203 
gravações em áudio das reuniões realizada pela $\mathrm{CoP}$, a observação participante e o diário de campo com anotações feitas pela pesquisadora durante e depois de cada encontro. Considerando a questão proposta para a pesquisa, a autora procurou identificar, em quais encontros do $2^{\circ}$ semestre de 2013, a discussão sobre a temática Resolução de Problemas esteve presente, a fim de, posteriormente, realizar a transcrição dos trechos em que se identificaram negociações de significados, envolvendo esse tema.

Dentre os empreendimentos conjuntos/articulados da CoP, engendrando a Resolução de Problemas, a autora destaca a realização de: uma pesquisa individual sobre a temática, um seminário sobre a Resolução de Problemas, a elaboração conjunta de um texto com a síntese das pesquisas realizadas e a produção de atividades para a sala de aula que considerassem a perspectiva da Resolução de Problemas.

Em relação ao empreendimento "a realização de uma pesquisa individual sobre a temática”, Silva (2015, p. 89) destaca ter identificado que tal empreendimento implicou em uma participação, no sentido apresentado por Wenger et al.(2002), em maior ou menor grau, de todos os membros da comunidade, pois todos tiveram que se engajar nele, atitude fundamental para os encaminhamentos seguintes.

O empreendimento "a realização de seminário sobre a Resolução de Problemas" foi um momento importante para evidenciar as negociações de significado envolvendo a temática, uma vez que cada membro da CoP compartilharia seu entendimento a partir do empreendimento "pesquisa individual sobre a temática". Silva (2015) destaca que, na interação, ficou evidente o fato de os professores de Matemática dos anos finais do Ensino Fundamental desconhecerem e não trabalharem com a Resolução de Problemas em suas aulas.

Essa constatação implicou no engajamento da $\mathrm{CoP}$ em um novo empreendimento: a elaboração conjunta de um texto com a síntese das pesquisas realizadas. O exposto por Silva (2015, p. 92) sugere que a CoP não se contentava em conhecer a temática pelas lentes teóricas, queria experimentá-la de outra "forma", iniciando, assim, um novo empreendimento, permeado por negociações de significado e reificações. Dessa forma, a CoP se engajou no empreendimento de "elaborar uma atividade para a sala de aula que considerasse a perspectiva da Resolução de Problemas".

Silva (2015, p. 97) aponta que, nesse processo, a CoP teve que negociar o entendimento em relação a problemas e exercícios, bem como a importância de ambos para a aprendizagem de conceitos matemáticos. Também destaca que, como cada uma das duas atividades tinha uma intencionalidade, a $\mathrm{CoP}$ necessitou negociar as diferentes concepções que a Resolução de Problemas pode assumir, tal como apontava o texto-síntese elaborado conjuntamente.

Contudo, é importante destacar que as negociações de significado, envolvendo a Resolução de Problemas, nem sempre ocorreram livres de conflitos, mas que a CoP sempre manteve um clima de respeito e de colaboração entre seus membros, tal como nos indica 
Silva (2015).

A pesquisa desenvolvida por Barros (2016) teve por objetivo investigar momentos de planejamento e reflexão, envolvendo a produção escrita realizada na Comunidade de Prática, e, dessa maneira, responder ao seguinte questionamento: "Que contribuições propiciadas pela produção escrita de professores e futuros professores que ensinam matemática podem ser identificadas em uma Comunidade de Prática?"

Para atingir seu objetivo, Barros (2016) levou em conta os seguintes instrumentos de coleta de dados: a) narrativas de memórias pessoais e profissionais; b) narrativas de trajetória do grupo e c) gravação e transcrição de encontros.

A autora selecionou quatro narrativas, que podem ser entendidas como empreendimentos conjuntos/articulados da CoP (Wenger, 1998). No que tange às narrativas de memórias, selecionou as intituladas "Memorial I" e "Eu e minha prática". Ambas foram produzidas pelos membros no período inicial de formação da CoP, em julho de 2013, e apresentam o contexto histórico de cada membro do grupo.

Barros (2016) também selecionou as narrativas denominadas "Trajetórias de formação I e II" por constituírem-se em memoriais que resgatam o percurso da CoP durante o semestre e são relevantes para a análise das formações no período destacado pela dissertação. Foram feitas leituras de todas as narrativas, e os trechos relevantes foram separados para análise. Além disso, a autora realizou uma análise das produções escrita em que a CoP se engajou no período de janeiro a outubro de 2015, que objetivavam a escrita de artigos e relatos de prática para apresentação em eventos científicos.

Com o intento de ampliar sua compreensão acerca das contribuições dessa escrita para a formação dos membros da CoP, Barros (2016) considerou, também, a transcrição das discussões e das reflexões realizadas em encontros da CoP posteriores à realização desses eventos.

Para analisar os dados coletados, Barros (2016) estabeleceu as seguintes categorias para compreender as contribuições do trabalho colaborativo: a) na produção escrita; b) na análise das práticas; c) nas reflexões sobre a prática; d) no engajamento profissional; e e) no desenvolvimento profissional.

Em linhas gerais, os resultados apontados por Barros (2016) indicam que, em contextos de CoP, escrever e refletir sobre as práticas possibilitam uma aproximação e um diálogo entre as questões cotidianas vivenciadas pelos professores e a produção de conhecimentos científicos. Barros (2016) aponta, ainda, que a reflexão coletiva sobre as práticas possibilitou uma ampliação do olhar dos membros por meio dos processos desencadeados de negociação de significado, e pelo próprio registro escrito ou oral (reificações).

Pela análise da pesquisa de Barros (2016), considerando o engajamento dos membros da $\mathrm{CoP}$, podemos perceber que a escrita sobre a própria prática se constituiu num ciclo de 
aprendizagens para os membros da CoP. Ciclo esse que se iniciou com a escrita de narrativas sobre a trajetória profissional e culminou com a apresentação de artigos e relatos de práticas em eventos científicos. Nesse direcionamento, Barros (2016) ressalta que, ao externar suas escritas em eventos, os membros da $\mathrm{CoP}$ experimentaram a segurança em suas posturas e em suas colocações. Para tanto, cada um dos membros sempre se sentia apoiado pelos demais, que complementaram e auxiliaram tanto no engajamento quanto no crescimento profissional propiciado por esses momentos.

Por fim, o estudo realizado por Tinti (2016) visou identificar e descrever algumas aprendizagens docentes evidenciadas na mesma Comunidade de Prática (CoP PUC-SP) para, então, analisar e discutir elementos do contexto dessa $\mathrm{CoP}$ que revelaram/permitiram tais aprendizagens. Para tanto, elegeu o seguinte questionamento: "Que aprendizagens docentes são evidenciadas nos estágios de desenvolvimento de uma CoP, constituída na PUC-SP a partir de um projeto aprovado no OBEDUC?"

Para atingir esse objetivo, Tinti (2016) realizou um recorte temporal dos encontros da CoP, gravados em áudio. Esse recorte temporal focou o período de junho de 2013 a dezembro de 2015, totalizando 40 encontros. Além disso, considerou como instrumento de coleta de dados os registros em um diário de bordo.

A organização dos dados foi realizada, segundo as ideias de Wenger, Mcdermott e Snyder (2002) acerca dos estágios de desenvolvimento de uma CoP, ou seja, para esses autores uma CoP pode passar por diferentes fases de desenvolvimento. O tempo de vida de uma CoP é relativo, pois está atrelado a diferentes fatores, como: interesse, dinâmica e orientação. Wenger et al. (2002) indicam que podem ser consideradas cinco fases consecutivas no tempo de vida de uma CoP, a saber: potencial, expansão, maturidade, sustentabilidade e transformação. Contudo, Tinti (2016) ressalta que os referidos estágios não possuem um tempo de duração definido a priori.

Na análise dos encontros da CoP PUC-SP, Tinti (2016) identificou que a comunidade passou pelos estágios Potencial, Expansão e de Maturidade. Em sua pesquisa, o autor apresenta uma descrição analítica de cada um desses estágios, possibilitando ao leitor o entendimento da dinâmica e do engajamento dessa CoP. Ao longo dessa descrição, Tinti (2016) sinaliza as aprendizagens docentes, mobilizadas pelo engajamento/compromisso mútuo dos membros da CoP com os empreendimentos articulados/conjuntos, propostos (negociados) pelos membros.

Dentre as aprendizagens docentes evidenciadas por Tinti (2016), destacamos: a escrita e a reflexão sobre a própria prática; a construção de mapas conceituais; a constituição e o pertencimento a uma CoP; o lidar com a diversidade de perfis e trajetórias dentro da CoP; a elaboração de atividades, produzidas individual e coletivamente, envolvendo a perspectiva da Resolução de Problemas; o estudo e o manuseio de materiais manipuláveis voltados ao ensino da matemática, mais especificamente ao conceito de número fracionário.

Além disso, Tinti (2016) aponta que as aprendizagens docentes mobilizadas nos 
estágios de desenvolvimento da CoP PUC-SP foram múltiplas e convergem para os conhecimentos da/para/na prática propostos por Cochran-Smith e Lytle (2009).

Considerando os componentes de uma CoP, optamos por sintetizá-los em quadros. O Quadro 4 apresenta, para cada uma das pesquisas, a indicação dos elementos que possibilitaram aos autores caracterizar o grupo como uma $\mathrm{CoP}$.

Quadro 4 - Análise de pesquisas desenvolvidas pelo Grupo de Pesquisa "Professor de Matemática: formação, profissão, saberes e trabalho docente" por meio da organização da CoP.

\begin{tabular}{|c|c|c|c|}
\hline Pesquisa & Membros da CoP & Domínio & Prática \\
\hline Silva (2015) & $\begin{array}{c}\text { Seis professores que } \\
\text { ensinam matemática na } \\
\text { Educação Básica, sendo três } \\
\text { dos anos iniciais e três dos } \\
\text { anos finais; três } \\
\text { licenciandos em Pedagogia; } \\
\text { três licenciandos em } \\
\text { Matemática; dois } \\
\text { mestrandos; dois } \\
\text { doutorandos; duas doutoras }\end{array}$ & $\begin{array}{l}\text { Formação de professores } \\
\text { que ensinam matemática na } \\
\text { Educação Básica }\end{array}$ & $\begin{array}{l}\text { Elaboração, validação e } \\
\text { implementação de } \\
\text { atividades envolvendo a } \\
\text { Resolução de Problemas }\end{array}$ \\
\hline $\begin{array}{l}\text { Barros } \\
(2016)\end{array}$ & $\begin{array}{c}\text { Licenciandos em } \\
\text { Matemática e em } \\
\text { Pedagogia, professores que } \\
\text { ensinam matemática na } \\
\text { Educação Básica e } \\
\text { pesquisadores em Educação } \\
\text { e Educação Matemática }\end{array}$ & $\begin{array}{l}\text { Prática de professores que } \\
\text { ensinam matemática na } \\
\text { Educação Básica }\end{array}$ & $\begin{array}{c}\text { Reflexão e } \\
\text { compartilhamento de } \\
\text { questões advindas da } \\
\text { prática e da profissão } \\
\text { docente }\end{array}$ \\
\hline Tinti (2016) & $\begin{array}{l}\text { Estudantes de licenciatura } \\
\text { em Matemática; estudantes } \\
\text { de Pedagogia; professores } \\
\text { que ensinam matemática na } \\
\text { Educação Básica; } \\
\text { estudantes de pós- } \\
\text { graduação e pesquisadores }\end{array}$ & $\begin{array}{l}\text { Formação de professores } \\
\text { que ensinam matemática, } \\
\text { situada nos processos de } \\
\text { ensino e de aprendizagem } \\
\text { da matemática e na reflexão } \\
\text { da/na/para prática docente }\end{array}$ & $\begin{array}{l}\text { (Variaram de acordo com } \\
\text { os estágios da CoP). } \\
\text { Produção de mapas } \\
\text { conceituais e narrativas; } \\
\text { leitura, reflexão e debate de } \\
\text { textos acadêmicos sobre o } \\
\text { ensino de matemática e } \\
\text { sobre a profissão docente; } \\
\text { negociação do trabalho } \\
\text { colaborativo, de uma } \\
\text { formação horizontal e de } \\
\text { um domínio para a } \\
\text { constituição da CoP }\end{array}$ \\
\hline
\end{tabular}

Fonte: elaborado a partir da análise das respectivas pesquisas.

No Quadro 5, expomos, para cada uma das pesquisas, a prática da $\mathrm{CoP}$, considerando os elementos indicados por Wenger (1998).

Quadro 5 - Análise de pesquisas desenvolvidas pelo Grupo de Pesquisa "Professor de Matemática: formação, profissão, saberes e trabalho docente" por meio das dimensões da prática da CoP

\begin{tabular}{|c|c|c|c|} 
Pesquisa & $\begin{array}{c}\text { Engajamento/ } \\
\text { compromisso mútuo }\end{array}$ & $\begin{array}{c}\text { Empreendimento } \\
\text { conjunto/articulado }\end{array}$ & Repertório compartilhado \\
\hline
\end{tabular}


DOI: http://dx.doi.org/10.20396/zet.v25i1.8647770

\begin{tabular}{|c|c|c|c|}
\hline Pesquisa & $\begin{array}{l}\text { Engajamento/ } \\
\text { compromisso mútuo }\end{array}$ & $\begin{array}{c}\text { Empreendimento } \\
\text { conjunto/articulado }\end{array}$ & Repertório compartilhado \\
\hline Silva (2015) & $\begin{array}{l}\text { Negociar empreendimentos } \\
\text { que permitam que os } \\
\text { membros se apropriem da } \\
\text { Resolução de Problemas, } \\
\text { como uma perspectiva } \\
\text { didático-metodológica para } \\
\text { o ensino de matemática }\end{array}$ & $\begin{array}{c}\text { Pesquisa individual e } \\
\text { seminário sobre a } \\
\text { Resolução de Problemas; } \\
\text { elaboração conjunta de um } \\
\text { texto com a síntese das } \\
\text { pesquisas realizadas; } \\
\text { produção de uma atividade } \\
\text { para a sala de aula que } \\
\text { considerasse a perspectiva } \\
\text { da Resolução de Problemas }\end{array}$ & $\begin{array}{l}\text { Texto síntese sobre a } \\
\text { Resolução de Problemas; } \\
\text { atividades a serem } \\
\text { implementadas nas salas de } \\
\text { aula, elaboradas pelos } \\
\text { membros, sob a perspectiva } \\
\text { da Resolução de Problemas }\end{array}$ \\
\hline $\begin{array}{l}\text { Barros } \\
(2016)\end{array}$ & $\begin{array}{l}\text { Produzir narrativas, } \\
\text { memoriais de formação, } \\
\text { artigos e relatos de prática } \\
\text { objetivando a reflexão } \\
\text { sobre a própria prática }\end{array}$ & $\begin{array}{l}\text { Elaboração de narrativas, } \\
\text { memoriais de formação, } \\
\text { artigos e relatos de prática }\end{array}$ & $\begin{array}{l}\text { Memoriais de formação, } \\
\text { narrativas individuais; } \\
\text { artigos e relatos de prática } \\
\text { apresentados em dois } \\
\text { simpósios }\end{array}$ \\
\hline Tinti (2016) & $\begin{array}{l}\text { (Variaram de acordo com } \\
\text { os estágios da CoP). } \\
\text { Engajar nos } \\
\text { empreendimentos } \\
\text { propostos inicialmente pelo } \\
\text { núcleo fixo da CoP; } \\
\text { definir "acordos" } \\
\text { envolvendo questões de } \\
\text { ética, de registro dos } \\
\text { encontros, da perspectiva } \\
\text { de colaboração e de } \\
\text { formação horizontal; } \\
\text { definir um domínio para a } \\
\text { CoP }\end{array}$ & $\begin{array}{l}\text { (Variaram de acordo com } \\
\text { os estágios da CoP). } \\
\text { Construção e análise de } \\
\text { mapa conceitual (“Ensino } \\
\text { da Matemática"); } \\
\text { escrita e socialização de um } \\
\text { memorial de formação; } \\
\text { escrita e socialização de } \\
\text { uma narrativa (“eu e minha } \\
\text { prática”); } \\
\text { leitura, reflexão e debate de } \\
\text { textos acadêmicos sobre o } \\
\text { ensino da matemática e a } \\
\text { profissão docente na } \\
\text { atualidade; } \\
\text { mapeamento de recursos } \\
\text { pedagógicos para o ensino } \\
\text { da Matemática; } \\
\text { elaboração de planos de } \\
\text { aula, envolvendo os blocos } \\
\text { de conteúdo dos PCN; } \\
\text { manutenção da prática de } \\
\text { organizar um momento de } \\
\text { pausa no grupo (café da } \\
\text { manhã) }\end{array}$ & $\begin{array}{l}\text { (Variaram de acordo com os } \\
\text { estágios da CoP). } \\
\text { Mapa conceitual (“Ensino } \\
\text { da Matemática"); } \\
\text { texto de autoria de Beatriz } \\
\text { D'Ambrósio; } \\
\text { texto de autoria de Bernard } \\
\text { Charlot; } \\
\text { impressões e troca de } \\
\text { experiências em relação aos } \\
\text { empreendimentos e à prática } \\
\text { docente }\end{array}$ \\
\hline
\end{tabular}

Fonte: elaborado a partir da análise das respectivas pesquisas.

\section{O que apontam as pesquisas analisadas?}

As pesquisas analisadas indicam que a constituição de espaços formativos a partir de contextos colaborativos tem se mostrado como uma alternativa para a superação de modelos tradicionais formativos, pautados na racionalidade técnica (Contreras, 2002), além de serem terrenos férteis para cultivar Comunidades de Prática.

Outro ponto que merece ser destacado se refere à constituição desses grupos. As Zetetiké, Campinas, SP, v.25, n1, jan./abr.2017, p.186-203 
pesquisas analisadas indicam que os grupos formados, a partir de projetos vinculados ao OBECUC, se constituíram em CoP. Algumas dessas pesquisas (Silva, 2015; Barros, 2016; Tinti, 2016) apontam que os membros da CoP eram professores em diferentes momentos da carreira docente, o que favoreceu a aproximação da formação inicial com a formação continuada e corroborou a concepção da formação de professores como um processo contínuum (Imbernón, 2010).

As pesquisas analisadas indicam que, embora o movimento de constituição das CoP tenha ocorrido de maneira diversificada, os empreendimentos em que se engajaram foram negociados em função das demandas formativas de seus membros. Nesse contexto, fica evidente um movimento de compromisso mútuo entre os membros da $\mathrm{CoP}$ em relação aos empreendimentos e à manutenção da comunidade, tal como apontam os estudos de Rocha (2013), Oliveira (2014) e Garcia (2014).

No tocante aos empreendimentos das CoP relatados pelas pesquisas, entendemos que parecem convergir para ações tais como nos aponta Silva (2015):

em contextos colaborativos como esses, formados por grupos heterogêneos, é possível desenvolver em conjunto uma série de ações práticas, como: realizar estudos teóricometodológicos, elaborar recursos didáticos, refletir sobre estratégias de ensino, produzir narrativas, problematizar sobre o processo formativo, refletir sobre a prática no sentido de aprimorá-la e melhorá-la, entre outras. Nesse processo, tanto acadêmicos quanto professores aprendem e contribuem com as interações e discussões. (p. 17)

Dessa maneira, as pesquisas analisadas destacam uma articulação entre os saberes da academia e os saberes da escola e da universidade. Além disso, evidenciam um movimento de circulação de tais saberes por outras comunidades em que transitam os membros das CoP investigadas.

É importante destacar, ainda, que percebemos um movimento de (co)responsabilidade formativa entre os membros das comunidades, ou seja, ao mesmo tempo em que eles são responsáveis por sua própria formação, também se responsabilizam pelo processo formativo dos demais membros da CoP, e esse processo é evidenciado nos engajamentos descritos nas pesquisas.

Ao olharmos para os empreendimentos conjuntos, indicados pelas pesquisas analisadas, fica evidente que eles emergiram das necessidades formativas dos docentes, refletindo no engajamento dos membros da $\mathrm{CoP}$ e, consequentemente, nas aprendizagens mobilizadas a partir das múltiplas negociações de significado em que ocorrem.

Em relação aos processos de negociação de significado entre os participantes de uma $\mathrm{CoP}$, as pesquisas corroboram as ideias de Fiorentini (2009), ao apontarem que o processo pode não ser harmonioso dentro da comunidade.

Isso não significa que eles sejam iguais ou constituam um agrupamento homogêneo. Cada um tem, por um lado, sua própria história, suas múltiplas identidades; seus próprios saberes e motivações pessoais para participar dessa comunidade; e, de outro, um forte relacionamento 
interpessoal com seus pares, embora ocorram com frequência ... situações de conflito, colaboração, tensão, autoritarismo, sinergia, sucesso, fracasso e amizade. (p. 240)

Como apontado, a negociação de significado em uma CoP é um processo permeado por momentos de tensão, conflito, dentre outros. Entretanto, as experiências analisadas apontam que as CoP sempre mantiveram um clima de respeito mútuo e colaboração, indicando uma importante componente para novos estudos: a afetividade manifestada em uma CoP.

Considerando a análise de aprendizagens docentes apresentadas nas pesquisas de Rocha (2013), Oliveira (2014), Garcia (2014) e Tinti (2016), identificamos que elas apontam a tendência de analisar os contextos das $\mathrm{CoP}$, contribuindo para a minimização do cenário apontado por Cyrino (2009,) de que " são poucas as pesquisas que buscam entender como os contextos de formação podem se constituir em um espaço fértil para os processos de negociação de significados como mecanismo para aprendizagem” (p. 107).

Em relação ao processo de análise das aprendizagens, dentre as pesquisas analisadas, a de Garcia (2014) centrou-se nas trajetórias de aprendizagens constituídas a partir de um empreendimento negociado pela CoP, denominado de "estudo do raciocínio proporcional". Já Tinti (2016) popôs uma análise levando em conta os possíveis Estágios de Desenvolvimento de uma CoP, tal como sinalizam Wenger et al. (2002).

Sobre os aspectos metodológicos das pesquisas, apuramos uma predominância pela abordagem qualitativa, o que nos parece compreensível, se olharmos para os referenciais teóricos adotados e para os objetivos, que se propõem analisar aprendizagens ocorridas no contexto das CoP. Observamos que a maioria das pesquisas utilizou como instrumentos de coleta de dados o diário de campo, as produções escritas pelos participantes e as transcrições de áudio dos encontros das CoP.

Além disso, é importante destacar a dificuldade encontrada para compor esse mapeamento. Pelo fato de as pesquisas analisadas se ancorarem na Teoria Social da Aprendizagem (Wenger, 1998) para compor as análises, os autores apresentam diferentes episódios em que seja possível evidenciar os processos de negociação de significado e, consequentemente, as aprendizagens mobilizadas. Assim, as pesquisas apresentam uma diversidade de dados, o que nos impõe uma limitação, haja vista que não é possível contemplá-los totalmente num estudo qualitativo do tipo mapeamento, como o que aqui apresentamos.

\section{Considerações finais}

As pesquisas analisadas sinalizam que os projetos desenvolvidos no âmbito do OBEDUC têm contribuído para a constituição de CoP. Há de se considerar que, embora os estudos de Rocha (2013), Oliveira (2014) e Garcia (2014) tenham sido desenvolvidos em contextos diferentes das pesquisas de Silva (2015), Barros (2016) e Tinti (2016), é possível perceber similitude entre eles.

De modo geral, os estudos apontam que, nesse espaço formativo, oriundos das CoP, 
os participantes se sentem motivados a aprender e a compartilhar experiências. Além disso, os estudos ressaltam o clima de respeito, colaboração, reflexão sobre/com/na prática, além da responsabilidade com a formação individual e coletiva dos membros das $\mathrm{CoP}$.

O mapeamento realizado indica que, no cenário nacional, o OBEDUC tem se constituído lugar de formação (Oliveira, 2015) para professores e futuros professores, sobretudo por fomentar e favorecer a consubstanciação de parcerias entre universidade e escola e, com isso, propiciar múltiplas e diversificadas experiências formativas, considerando as necessidades dos envolvidos.

Refletindo sobre todas as contribuições que o OBEDUC tem possibilitado à formação de professores e, ainda, diante do cenário econômico e político em que nosso país se encontra atualmente, reiteramos aqui a importância de continuidade e de expansão desse programa, para que muitos outros professores possam se inserir em espaços formativos que os enxerguem como protagonistas de sua formação e, consequentemente, de suas aprendizagens.

\section{Referências}

Contreras, J. (2002). A autonomia de professores. São Paulo: Cortez.

Cyrino, M. C. C. T. (2009). Comunidades de prática de professores como espaço de investigação sobre a formação de professores de matemática. In I. L. Batista, \& R. F. Salvi (Org.), Pós-graduação em ensino de ciências e educação matemática: um perfil de pesquisas (pp. 95-110). Londrina: EDUEL.

Fiorentini, D. (2009). Quando acadêmicos da universidade e professores da escola básica constituem uma comunidade de prática reflexiva e investigativa. In D. Fiorentini, R. C. Grando, \& R. G. S. Miskulin. Práticas de formação e de pesquisa de professores que ensinam matemática (pp. 233-256). Campinas, SP: Mercado das Letras.

Imbernón, F. (2010). Formação docente e profissional: formar-se para a mudança e a incerteza. São Paulo: Cortez.

Lerman, S. (2010). Theories of mathematics education: is plurality a problem? In S. Brarath, \& L. English (Org.), Theories of Mathematics Education (pp.99-116). Berlim: Springer.

Oliveira, A. M. P. (2015). Desenvolvimento profissional de professores que ensinam matemática: colaboração e materiais curriculares no âmbito do Programa Observatório da Educação (OBEDUC). Anais da $25^{a}$ Reunião Anual da ANPEd. Caxambu: Associação Nacional de Pós-Graduação e Pesquisa em Educação.

Wenger, E. (1998). Communities of Practice: learning, meaning, and identity. New York: Cambridge University Press.

Wenger, E., Mcdermott, R., \& Snyder, W. M. (2002). Cultivating communities of practice. Boston: Harvard Business School Press. 


\section{Apêndice 1: Relação das teses e dissertações do corpus de análise deste estudo}

Barros, M. A. T. (2016). Processo de produção escrita de professores que ensinam matemática em grupos de pesquisa. Dissertação de Mestrado em Educação Matemática, Pontifícia Universidade Católica de São Paulo, São Paulo.

Garcia, T. M. R. (2014) Identidade profissional de professores de matemática em uma comunidade de prática. Tese de Doutorado em Ensino de Ciências e Educação Matemática, Universidade Estadual de Londrina, Londrina.

Oliveira, L. M. C. P. (2014). Aprendizagens no empreendimento estudo do raciocínio proporcional. Dissertação de Mestrado em Ensino de Ciências e Educação Matemática, Universidade Estadual de Londrina, Londrina.

Rocha, M. R. (2013). Empreendimentos de uma comunidade de prática de professores de matemática na busca de aprender e ensinar frações. Dissertação de Mestrado em Ensino de Ciências e Educação Matemática. Universidade Estadual de Londrina, Londrina.

Silva, W. R. (2015). Observatório da Educação da PUC/SP e a formação de professores que ensinam matemática em comunidades de prática. Dissertação de Mestrado em Educação Matemática, Pontifícia Universidade Católica de São Paulo, São Paulo.

Tinti, D. S. (2016). Aprendizagens docentes situadas em uma comunidade de prática constituída a partir do OBEDUC. Tese de Doutorado em Educação Matemática, Pontifícia Universidade Católica de São Paulo, São Paulo. 